\title{
Impact of integrated soil and water conservation program on crop production and income in West Harerghe Zone, Ethiopia
}

\author{
Yenealem Kassa $^{1,}{ }^{*}$, Fekadu Beyene ${ }^{1}$, Jema Haji ${ }^{2}$, Belaineh Legesse ${ }^{2}$ \\ ${ }^{1}$ Department of Rural Development and Agricultural Extension, Haramaya University, Ethiopia \\ ${ }^{2}$ Department of Agricultural Economics, Haramaya University, Ethiopia
}

Email address:

yenealemkassa@yahoo.co.uk (Yenealem K.), keneefb@yahoo.com (Fekadu B.), jemmahaji@gmail.com (Jema H.), belaineh.legesse@yahoo.com (Belaineh L.)

\section{To cite this article:}

Yenealem Kassa, Fekadu Beyene, Jema Haji, Belaineh Legesse. Impact of Integrated Soil and Water Conservation Program on Crop Production and Income in West Harerghe Zone, Ethiopia. International Journal of Environmental Monitoring and Analysis.

Vol. 1, No. 4, 2013, pp. 111-120. doi: 10.11648/j.ijema.20130104.11

\begin{abstract}
Land degradation has been identified as one of the most serious problems that threaten the sustainability of agriculture in Ethiopia. In an effort to address these problems, the basic paradigm and approach to soil and water conservation has itself evolved over time. In recent years more holistic and land-scape wide approaches that go beyond resource conservation towards improved land husbandry and water management for beneficial conservation have been promoted using a national guideline known as Community Based Participatory Watershed Development, where its impact is yet to be seen. In this respect, after having worked for many years on the core part of land management practices, some projects realized the need for value adding and natural resources management (NRM)-based income generation at household level. Hence, the major concern of this study was to evaluate the impact of those integrated land management interventions on crop production value per hectare and annual gross income of smallholder farm households in West Harerghe Zone of Oromia National Regional State. To meet this objective a total of 398 sample households, consisting 183 soil and water conservation program and 215 non-program participants, were randomly selected from nine program and nine counterfactual kebeles in three districts (DaroLabu, Messela and Oda Bultum). Descriptive statistics with appropriate statistical tests and propensity score matching (PSM) were used to meet the stated objective. Results of the descriptive statistics showed that before matching there was difference between program and non-program households in terms of sex, education, farming experience, land holding and livestock ownership. Estimates of propensity score matching (PSM) indicate the existence of a positive additional significant crop production value premium of birr 1,510.42 (US\$ 80.55) per hectare and annual gross income of birr 4,288.29 (US\$ 228.7) for program groups compared to non-program groups. This indicates that on average participant households earned 8.3 percent more crop production value per hectare and 21.2 percent more gross household income than their matches. The independent analysis result of the data also revealed that the value of crop production was fairly higher on moisture stress program kebeles $(1,771.35 \mathrm{~EB} /$ hectare) than in the high rainfall areas of the program $(1,439.28 \mathrm{~EB} /$ hectare). Therefore, in agriculture dependent country like Ethiopia, soil and water conservation is crucial in improving the livelihoods of the rural farm households. However, to realize the intended outcomes, agro-ecology specific technologies that are linked with natural resource management based income generating activities should be promoted.
\end{abstract}

Keywords: Ethiopia, Soil and Water Conservation, Crop Production, Propensity Score Matching

\section{Introduction}

Degradation of the Earth's surface (i.e. land degradation) is one of the most severe global problems of our times [1, 2 ], which affects $33 \%$ of the land surface; with consequences for more than 2.5 billion people [3]. About
$40 \%$ of the world's agricultural land is seriously degraded, where $80 \%$ of this degradation is caused by soil erosion [ 4 , 5]. This worldwide depletion of land resources continues to be a serious hazard, particularly, in the least developing countries, where agriculture is the main pillar of their economy $[1,6]$. Perhaps nowhere have these effects been 
deeper or have they created greater hardship than the farm population of Sub-Saharan African (SSA) countries [7]. Land degradation in Ethiopia accounts for $8 \%$ of the global total [8]. The most serious problem concerning country's land resources, however, is the removal of fertile topsoil by water. This is much more severe in the highlands where, $85 \%$ of the human and $77 \%$ of livestock population are living and agriculture is intensive [9]. As estimates from nationallevel studies indicate, more than 2 million ha of Ethiopia's highlands have been degraded beyond rehabilitation, and an additional 14 million hectares severely degraded, which is reflected in cereal yield reduction averaging less than 1.2 tons per hectare in most of the highlands [10]. The comparative analysis report of a decade by Environmental Forest Development on the cost of land degradation also indicated that, the net amount of soil eroded in 1995 was 130 million metric tons and this has increased to 182 million metric tons in 2005 and the nutrient loss from lost soil in terms of phosphorus and nitrogen was 1.1 and 1.3 million metric tons respectively. The monetary value of productivity loss, due to soil loss, also shows 639 and 766 million Birr in 1995 and 2005, respectively [11].

As a result of this extensive land degradation, which in turn are caused by various intermingled factors, soil productivity has been negatively affected and agricultural production has not been able to meet the basic food requirements of the growing population. This has significantly contributed to the hunger faced by some five to seven million people in the country, thereby requiring external assistance every year for their survival and more than $45 \%$ of the total population to toil below the absolute poverty line [12].

In response, governments and development agencies have invested substantial resources in promoting soil conservation practices as part of efforts to improve environmental conditions and ensure sustainable and increased agricultural production [13]. Despite the increasing efforts made and the growing policy interest, adoption of those technologies by smallholder farmers outside of intensively supported project locations has generally been. Regardless of all those efforts, the natural resource base is deteriorating from time to time and becomes major causes for food insecurity and vulnerability $[14,15]$.

Studies conducted in different parts of the country cameup with different factors that explain the low level of success of conservation initiatives - ranging from the poor performance of the technologies themselves to policy and institutional deficiencies at different levels [16, 12, 17, 18, 14]. The interventions were primarily technology oriented and top-down with limited participation of the beneficiaries in decision making [15]. Such command and control type of policies that have not been linked to the indigenous land conservation knowledge of the farmers as well as their local institutions, made the people to have limited sense of responsibility over the assets created [16, 10]. Policies, programs and projects for sustainable land management were also designed without making a distinction between proximate and underlying causes. This in turn obliged the technologies to focus narrowly on structural measures to arrest soil erosion only, without fully considering the underlying causes of low soil productivity, socio-economic factors, and the need for tangible benefits to be attractive to poor farmers [15]. However, although many scholars raised different factors affecting the sustainability of conservation measures, the major problems with past conservation efforts are largely rooted in a lack of understanding of the important interface between resource conservation and agriculture, and of the factors that motivate farmers to invest in sustainable land management over the long run $[12,17,15]$.

In an effort to address these problems, the basic paradigm and approach to land and water conservation has evolved over time [18]. In recent years, the Ethiopian government has changed its land management policy to a more holistic and land-scape wide approaches that go beyond resource conservation towards improved land husbandry and water management for beneficial conservation [19, 20]. Given this strategy, different sustainable land management programs have been implemented throughout the country. The central question is thus, do these land conservation interventions have an impact in improving crop production in value per hectare and gross annual income of participating households? If yes, how much is the impact? Answering these questions empirically would be of interest to program administrators and policy makers in promoting a major change in the preceding approaches. Against this backdrop, this study was carried out in West Harerghe Zone of Oromia Regional State, where various conservation programs have been executing aiming at improving the livelihoods of most vulnerable households though value adding and natural resources management (NRM)-based income generation at household level.

\section{Research Methodology}

\subsection{Description of the Study Area}

West Harerge Zone is one of the 17 Zones in Oromia National Regional State, geographically located between 70 32 ' - $9047^{\prime} \mathrm{N}$ latitude and 410 24' - $43048^{\prime} \mathrm{E}$ longitudes (between 70 52' 15" - 9028'43" North latitude and 400 03' 33" - 40034'13" East longitudes. The capital town of the Zone is Chiro, which is located at a distance of $326 \mathrm{~km}$ East of Addis Ababa. The area coverage of the Zone is $1,723,145 \mathrm{ha}(17,231 \mathrm{~km} 2)$, comprising of 14 districts with a combined population of $1,871,706$, of whom 912,845 are women. While 160,895 or $9.36 \%$ are urban inhabitants, a further 10,567 or $0.56 \%$ are pastoralists [21]. West Harerghe is subdivided in to three major climatic zones known to be Temperate tropical highland locally known as dega (12.49\%), Semi-temperate/Tropical rainy mid land or woinadega $(38 \%)$, and Semi-arid/Tropical dry or kola 
(49.5\%). The topography of the zone is characterized by steep slopes in the highlands and mid-highlands and large plains in the lowland areas. The ecological zones are set based on the differences in altitude variation ranging between 500 up to 3500 meters above sea level kola (500 $1500 \mathrm{~m}$ a.s.1), woinadega (1500 - $2300 \mathrm{~m}$ a.s.l) and dega (2300 - $3500 \mathrm{~m}$ a.s.1). The mean monthly minimum temperature ranging from $16^{\circ} \mathrm{C}$ to $20^{\circ} \mathrm{C}$, while the mean maximum is $24^{\circ} \mathrm{C}$ to $28^{\circ} \mathrm{C}$. Rainfall is dispersed throughout the year into two rainy seasons belg rains falling in February-April and meher or main season rains fall from June-September with small showers in dry months. Annual rainfall averages range from below $700 \mathrm{~mm}$ for the lower kolla to nearly $1,200 \mathrm{~mm}$ for the higher elevations of woinadega and dega areas. The rainfall is variable from year to year both in terms of intensity and distribution during the growing seasons causing a wide range of climatic hazards [22].

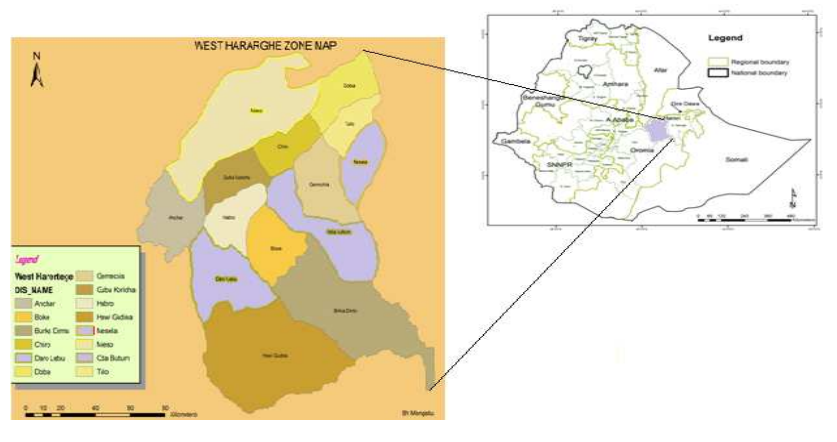

Figure 1. Map of Ethiopia and West Harerghe Zone

\subsection{Sampling Procedure}

Both purposive and multi-stage stratified sampling techniques were used to collect primary data. Considering the objective of the study and representativeness of the sample, out of the 14 districts in the zone, three pastoral woredas were excluded and the study focused on the remaining 11 (eleven) non-pastoral woredas. Based on this, in the first stage, three woredas were selected randomly in consultation with West Hararghe Zone Natural Resource Development Office in Chiro (Asebe Teferi). Accordingly Messela, Oda Bultum and Daro Lobu districts were selected. Second, from the sampled districts, all kebeles where soil erosion is severe and many conservation strategies of land management have been undertaken were selected purposely (to increase the chance of sampling adopters). Yet again, from among these kebeles, nine kebeles were chosen randomly. Concurrently, nine comparison Kebeles were chosen purposively based on their close similarity to the conserved Kebeles in their social, infrastructure, agro-climatic and economic characteristics. Accordingly, data was collected from both households participating and non-participating in conservation strategies of land management using the same interview schedule at the same time. To give equal chance in selection of the study units from each concerned woredas, probability proportional to size (PPS) was applied. Again PPS was used to draw sampling units proportionally from each kebele administration of the three woredas. Consequently, the total sample size, 398 households were randomly drawn from each KA using simple random sampling procedure via sampling frame (183 households of direct participants and 216 non-participant households).

\subsection{Data Analysis}

To measure the impact of conservation strategies of land management on rural households' livelihood, Propensity Score Matching (PSM) technique was employed. The PSM technique enables us to extract from the sample of nonparticipating households a set of matching households that look like the participating households in all relevant preintervention characteristics. The study attempted to estimate the average impact of treatment on treated ${ }^{1}$ (ATT). The word "treatment" implies participation in the program, which is soil and water conservation program, and "impact" is meant for the change on crop production value per hectare and annual gross household income as an outcome indicator. On the other hand, "control" stands for nonparticipant/non-treated households that used for comparison. Following [23], when estimating ATT there are five steps to be followed.

\subsubsection{Estimation of Propensity Score}

The first step in estimating the treatment effect is to estimate the propensity score. To get this propensity scores any standard probability model can be used (for example, logit, probit or multi-nominal logit) [24]. As the propensity to participate is unknown, the first task in matching is to estimate this propensity scores. Matching can be performed conditioning on $\mathrm{P}(\mathrm{X})$ alone rather than on $\mathrm{X}$, where $\mathrm{P}(\mathrm{X})=$ Prob $(D=1 \mid X)$ is the probability of participating in the program conditional on $\mathrm{X}$. If outcomes without the intervention are independent of participation given $\mathrm{X}$, then they are also independent of participation given $\mathrm{P}(\mathrm{X})$. This reduces a multidimensional matching problem to a single dimensional problem [25].

In this study logit model was used to estimate propensity scores using a composite of pre-intervention characteristics of the sampled households [25], and matching was then performed using propensity scores of each observation. In estimating the logit model, the dependent variable was participation, which takes the value of 1 if a household participated in the program and 0 otherwise. The mathematical formulation of logit model is as follows:

$$
\mathrm{Pi}=\frac{e^{Z_{i}}}{1+e^{Z_{i}}}
$$

Where, Pi is the probability of participation,

\footnotetext{
${ }^{1}$ According to Bryson et al. (2002), ATT refers to mean impact of the program on individuals who actually participated.
} 


$$
\mathrm{Z}_{i}=\mathrm{a} 0+\sum_{i=1}^{n} \mathrm{ai} \mathrm{X}_{i}+\mathrm{U}_{i}
$$

Where, $i=1,2,3, \cdots, n$

$\mathrm{a} 0=$ intercept

$\mathrm{ai}=$ regression coefficients to be estimated

$\mathrm{Ui}=\mathrm{a}$ disturbance term, and the probability that a household belongs to non-program group is:

$$
1-\mathrm{P}_{\mathrm{i}} \frac{1}{1+\mathrm{e}^{\mathrm{z}_{\mathrm{i}}}}
$$

The logit model via which the propensity score is generated should include predictor variables that influence the selection procedure or participation in the program and the outcome of interest [26, 27].

\subsubsection{Choice of Matching Algorithm}

Estimation of the propensity score per se is not enough to estimate the ATT of interest. This is due to the fact that propensity score is a continuous variable and the probability of observing two units with exactly the same propensity score is, in principle, zero. Various matching algorithms have been proposed in literature to overcome this problem. The most commonly applied matching estimators are Nearest Neighbour (NN) Matching, Caliper Matching and Kernel matching. The methods differ from each other with respect to the way they select the control units that are matched to the treated, and with respect to the weights they attribute to the selected controls when estimating the counterfactual outcome of the treated. However, they all provide consistent estimates of the ATT under the CIA and the overlap condition [23]. The choice should be guided in part by what the distribution of scores in the comparison and treatment samples looks like.

\subsubsection{Overlap and Common Support}

Imposing a common support condition ensures that any combination of characteristics observed in the treatment group can also be observed among the control group [26]. It requires deleting all observations out of the overlapping region, whose propensity scores are smaller than the minimum and larger than the maximum, of the treatment and control groups respectively [23].

\subsubsection{Testing the Matching Quality}

Matching quality has to be checked if the matching procedure is able to balance the distribution of the relevant variables in both the control and treatment group, since conditioning is not on all covariates but on the propensity score [23]. There are different approaches in applying the method of covariate balancing (i.e., the equality of the means on the scores and all the covariates) between treated and non-treated individuals. Among different procedures the most commonly applied ones are; Standard bias, t-test, joint-significance and pseudo- $\mathrm{R}^{2}$. Furthermore, different researchers become increasingly aware that it is important to test the robustness of results to departures from the identifying assumption. Since it is not possible to estimate the magnitude of selection bias with non-experimental data, the problem can be addressed by sensitivity analysis. The basic idea of all approaches is to compare the situation before and after matching and check if there remain any differences after conditioning on the propensity score.

\subsubsection{Estimating the Average Treatment Effect on the Treated}

Following the literature of program evaluation, let $Y_{1}$ be crop production value per hectare when the individual $i$ is subject to treatment $(\mathrm{C}=1)$ and $\mathrm{Y}_{0}$ the same variable when an individual is exposed to the $\operatorname{control}(\mathrm{C}=0)$. The observed outcome is

$$
\mathrm{Y}=\mathrm{CY} 1+(1-\mathrm{C}) \mathrm{Y}_{0}
$$

When $(\mathrm{C}=1)$ we observe $\mathrm{Y} 1$; when $(\mathrm{C}=0)$ we observeY $\mathrm{Y}_{0}$. Our goal is to identify the average effect of treatment (ATT) on program and non-program households. It is defined as:

$$
\mathrm{ATT}=\mathrm{E}\left(\mathrm{Y}_{1}-\mathrm{Y}_{0} \mid \mathrm{C}=1\right)=\mathrm{E}\left(\mathrm{Y}_{1} \mid \mathrm{C}=1-\mathrm{E}\left(\mathrm{Y}_{0}=1\right.\right.
$$

The evaluation problem is that we can only observe $\mathrm{E}\left(\mathrm{Y}_{1} \mid \mathrm{C}=1\right)$ however $\mathrm{E}\left(\mathrm{Y}_{0} \mid \mathrm{C}=1\right)$; does not exist in the data, since it is not observed. A solution to this problem is to create the counterfactual, by matching treatment and control households. As discussed by Heckman [28], a critical assumption in the evaluation literature is that the no-treatment state approximates the no program state (4). For matching to be valid certain assumptions must hold. The primary assumption underlying matching estimators is the Conditional Independence Assumption (CIA). CIA states that the decision to adopt is random conditional on observed covariates X (Wooldridge, 2002). In notation,

$$
\left.\left(\mathrm{Y}_{1}, \mathrm{Y}_{0}\right) \mathrm{C} \mid \mathrm{X}\right)
$$

This assumption implies that the counterfactual outcome in the treated group is the same as the observed outcomes for non-treated group.

$$
\mathrm{E}\left(\mathrm{Y}_{0} \mid \mathrm{X}, \mathrm{C}=1\right) \mathrm{E}\left(\mathrm{Y}_{0} \mid \mathrm{X}, \mathrm{C}=0\right)
$$

This assumption rules out selection into the program on the basis of unobservable gains from participation. The CIA requires that the set of explanatory variables (X) should contain all the variables that jointly influence the outcome with no-treatment as well as the selection into treatment. Under the CIA, ATT can be computed as follows:

$$
\mathrm{ATT}=\mathrm{E}\left(\mathrm{Y}_{1}-\mathrm{Y}_{0} \mid \mathrm{X}, \mathrm{C}=1\right) \mathrm{E}\left(\mathrm{Y}_{1} \mid \mathrm{X}, \mathrm{C}=1\right)-\mathrm{E}\left(\mathrm{Y}_{0} \mid \mathrm{X}, \mathrm{C}=1\right)
$$

Matching individuals based on observed covariates might not be desirable or even feasible when the dimensions of the covariates are many. To overcome the problem of dimensionality, Rosenbaum and Rubin [25] show that instead of matching along $\mathrm{X}$, one can match along $\mathrm{P}(\mathrm{X})$, a single index variable that summarizes covariates. This index is known as propensity score (response probability). It is the conditional probability that household i adopts ponds/well given covariates: 
$\mathrm{P}(\mathrm{X})=\mathrm{P}[\mathrm{C}=1 \mid \mathrm{X}]$.

The ATT in equation (7) can then be written as:

$$
\mathrm{ATT}=\mathrm{E}\left(\mathrm{Y}_{1} \mid \mathrm{P}(\mathrm{X}), \mathrm{C}=1\right)-\mathrm{E}\left(\mathrm{Y}_{0} \mid \mathrm{P}(\mathrm{X}), \mathrm{C}=1\right.
$$

The intuition is that two individual households with the same probability of adoption will show up in the treated and untreated samples in equal proportions.

Finally, using predicted probabilities of participation in the program (i.e. propensity score) match pairs are constructed using alternative methods of matching estimators. Then the impact estimation is the difference between simple mean of outcome variable of interest for program and non-program households. In our case, the mean stands for household crop production value and gross household income. The difference involvement in soil and water conservation technologies between program and matched non-program households is then computed. The ATT is obtained by averaging these differences in participants' outcomes $\left(\mathrm{Y}_{\mathrm{i}}\right)$ across the $\mathrm{k}$ matched pairs of households as follows:

$$
\operatorname{ATT}=\sum_{j=1}^{\mathrm{p}}\left(\mathrm{Y}_{\mathrm{ij} 1}-\sum_{\mathrm{i}=1}^{\mathrm{NP}} \mathrm{Y}_{\mathrm{ij} 0}\right) / \mathrm{p}
$$

Where, ATT is crop production value per hectare and gross household income, $\mathrm{Yij}_{1}$ is the post intervention on crop production value per hectare and gross income of household $\mathrm{j}, \mathrm{Yij}_{0}$ is the crop production and gross income of household of the $i^{\text {th }}$ non-program attached to the $j^{\text {th }}$ participant, NP is the total number of non-program and $\mathrm{P}$ is the total number of program. A positive (negative) value of ATT suggests that households who have participated in soil and water conservation program have higher (lower) outcome variable than non-programs.

On the basis of the various studies reviewed, it was hypothesized that both farmer's participation in the soil and water conservation program and maximization of their crop and gross income and are influenced by the combined effect of a number of factors. Thus, those specific hypotheses set for the selected variables and their prior expectations are described as follows:

$\mathrm{X}_{1}$ SEX (sex of the household head) $(+)$

$\mathrm{X}_{2}$ EDUC (education level of the household head) $(+)$

$\mathrm{X}_{3}$ FARMEXP (farming experience of the household head) $(+/-)$

$\mathrm{X}_{4}$ FAMSIZE(total family size of the householde) $(+)$

$\mathrm{X}_{5}$ DEPRATIO(dependency ratio, the ratio of nonactive labor to working) (-)

$\mathrm{X}_{6}$ LANDSIZE (area of land in hectares $(+)$

$\mathrm{X}_{7}$ TLUs (number of livestock owned) $(+/-)$

$\mathrm{X}_{8}$ EROPERCP (erosion problem as perceived by the farmer) $(+)$

$\mathrm{X}_{9}$ DISFTC (average distance of extension agents Office) (-)

$\mathrm{X}_{10}$ DISPLOT (average distance to pots) (-)

\section{Results and Discussion}

\subsection{Descriptive Statistics}

Results of the descriptive statistics showed that before matching there was difference between program and nonprogram households in terms of sex, farming experience of the household heads, family size, land holding and livestock ownership. The most widely and intensively used improved land management practices by the program participants $(\mathrm{n}=183)$ were fanya juu ${ }^{2}$, soil bud ${ }^{3}$, stone bund, check dam and farm forestry. Out of them 71.0 percent, 53.5 percent, 48.6 percent and 7.1 percent uses soil bund/stone faced soil bund, stone bund, fanya juu and check dam. As well, majority (98 percent) of these households adopted grass strip, mostly with soil and stone bunds and 58.5 percent of them planted different trees on their farm. From the users of the program, only 33.9 percent of the respondents were used a single conservation strategy, while (66.1 percent) used combinations of two, three and more conservation strategies on their plots. Moreover, in realizing the need for value adding and natural resources management (NRM)-based income generation at household level, the projects linking natural resource management with fruit tree promotion, animal fattening, improved poultry and improved apiculture production, fuel saving stoves and other income generating activities through different community based institutions. As a result, 92 percent of the sampled program participants were involved at least in one of these activities.

\subsection{Estimation Results}

Before proceeding to the estimation process, appropriate diagnostic measures were used on the data and the independent covariates. Accordingly, eleven outlying observations (seven observations from program participants and four observations from non-participants) with extreme influence (residual value of $>2.5$ ) were discarded from analyses. Results of multicollinearity test using the values of the variance inflation factor (VIF) showed that there was no serious problem of multicollinearity. Similarly, hetroscedasticity test was done using Breusch-Pagan and the P-value was 0.6098 which is insignificant indicating the absence of the problem of hetroscedasticity.

\subsubsection{Estimation of the Propensity Scores}

The logistic regression model specified in equation (5) was employed to estimate propensity scores for matching treatment household with control households. The dependent variable in this model was a dummy variable indicating whether the household has been in the conservation strategies of land management program which takes a value of 1 and 0 , otherwise. The explanatory variables used are variables that explain soil and water

\footnotetext{
${ }^{2}$ Faniajuu is a terrace made by digging ditches and trenches along the contour and throwing the soil uphill to form an embankment.

${ }^{3} \mathrm{~A}$ bund is a barrier that prevents soil and water from escaping the plot.
} 
conservation participation characteristics of the farm households. The logit estimate result appears to perform well for the intended matching exercise. The pseudo- $\mathrm{R}^{2}$ value 0.2008 shows that the competing households do not have many distinct characteristics overall, so that finding a good match between the treated and non-treated households becomes easier.

The maximum likelihood estimate of the logistic regression model result shows that program participation status has been significantly influenced by five variables (Table 1). Sex of household head, farming experience, size of cultivated land, distance from office of extension agents, and number of livestock holding in tropical livestock unit affect the probability of adopting conservation technologies Ownership of large farm size and farming experience affected participation positively at $1 \%$ significance level. Whereas the FTC distance from farmers plots determine the participation negatively at $1 \%$ significance level. Similarly, Sex of household head and livestock influenced the probability of soil and water conservation participation positively and significantly at 5\%. Meaning those farmers who have better farm experience, having larger land holding and living relatively near to office of extension agents have high chance of being participant. In addition, households having more number of livestock and male headed are more likely to be participant in conservation strategies of land management interventions.

Table 1. Logit estimates of the propensity scores

\begin{tabular}{llll}
\hline Variables & Coef. & Std. Err & $\mathbf{Z}$ \\
\hline Sex & 1.347261 & .5744699 & $2.35^{* *}$ \\
Education & .30249 & .2397622 & 1.26 \\
Farm experience & .0564162 & .0148324 & $3.80^{* * *}$ \\
Family size & -.0001096 & .0614306 & -0.00 \\
Dependency ratio & -.1982986 & .1493985 & -1.33 \\
Land size & .9990616 & .3028573 & $3.30^{* * *}$ \\
Livestock in TLU & .2557058 & .1023559 & $2.50^{* *}$ \\
Erosion perception & .2879915 & .240823 & 1.20 \\
Distance to pots & -.0329202 & .2091472 & -0.16 \\
Distance of FTC & -1.883405 & .3079087 & $-6.12^{* * *}$ \\
cons & -2.794246 & .8144358 & 0.001 \\
Number of obs & 387 & & \\
LRChi ${ }^{2}$ (10) & 109.97 & & \\
Prob $>$ Chi2 & 0.0000 & & \\
Log likelihood & -211.67698 & & \\
Pseudo R2 & 0.2062 & & \\
\hline
\end{tabular}

*** and ** indicate the level of significance at 1 and 5 percent, respectively.

"Fig. 2" shows the distribution of propensity scores of both treatment and control observations before common support condition is imposed. Most of treatment households are found in the right side of the distribution, whereas most of the control households are found partly in the centre and partly in the left side of the distribution. The figure also shows that there is wide area in which the propensity score of both the treatment and the control groups are similar. Hence it is possible to match the two groups using the common support region.

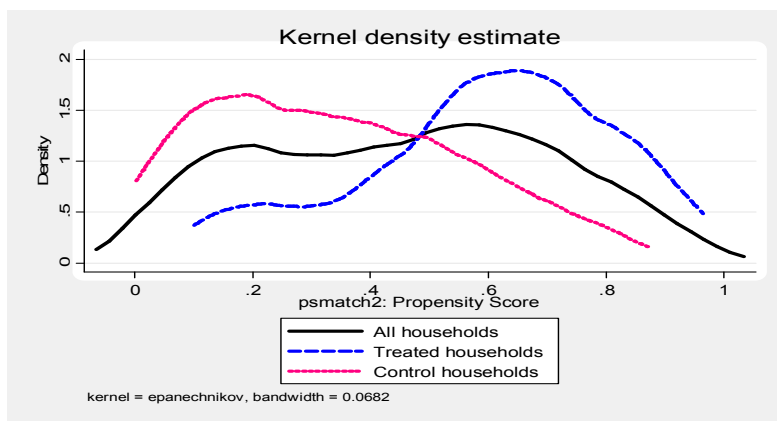

Figure 2. Kernel density of propensity scores

In setting the common support conditions the minima and maxima comparison was made. The basic criterion for determining the common support is to delete all observations whose propensity score is smaller than the minimum of the program and larger than the maximum in the opposite group [23]. The estimated propensity scores as shown in Table 2 vary between 0.0793 and 0.9660 (mean $=$ 0.5895 ) for program households and between 0.0008 and 0.8776 (mean $=0.3424$ ) for non-program households. Therefore our common support region would then lie between 0.0793 and 0.8776 . As a result of this restriction, 41 households (19 program and 22 control households) were dropped from the analysis in estimating the average treatment effect.

Table 2. Distribution of estimated propensity scores

\begin{tabular}{lllll}
\hline Groups & Obs. & Mean & Min & Max \\
\hline All households & 387 & .4547804 & .0007543 & .9660464 \\
Participants & 176 & .5895123 & .0792587 & .9660464 \\
Non-participants & 211 & .3423973 & .0007543 & .8776269 \\
\hline
\end{tabular}

"Fig. 3a" and "Fig. 3b" portray the distribution of estimated propensity scores, with and without the imposition of the common support condition, for program and non-program households, respectively. Most of the program households have propensity score around 0.5 whereas a significant majority of the non-program households have propensity score less than 0.5 .

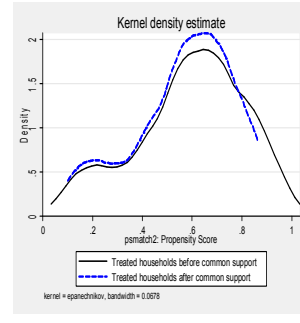

a

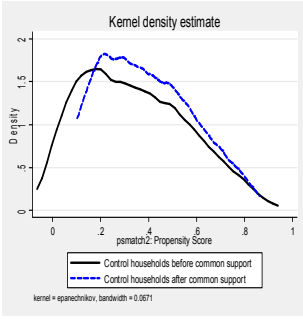

Figure 3. Density of propensity scores after matching 
The alternative matching estimators (algorithms) were searched in matching the treatment and control households in the common support region. The final choice of a matching estimator was guided by three criteria namely: the equal mean test (balancing test), pseudo- $\mathrm{R}^{2}$ and matched sample size [23]. A matching estimator which balances all explanatory variables (i.e., results in insignificant mean differences between the two groups), bears a low pseudo- $\mathrm{R}^{2}$ value and also results in large matched sample size is preferable.

In line with the above indicators of matching quality, kernel matching (bwidth 0.5), was found to be the best matching algorithm for the data. Therefore, all the estimation results and discussions would be outcome the of kernel matching algorithm with band width 0.5 .

Table 3. Performance of matching estimators

\begin{tabular}{llll}
\hline Matching Estimator & \multicolumn{2}{l}{ Performance Criteria } & \\
& $\begin{array}{l}\text { Balancing } \\
\text { test* }\end{array}$ & Pseudo-R & $\begin{array}{l}\text { Matched } \\
\text { sample size }\end{array}$ \\
\hline NN(1) & 5 & 0.141 & 346 \\
NN(2) & 5 & 0.143 & 346 \\
NN(3) & 5 & 0.145 & 346 \\
NN(4) & 5 & 0.144 & 346 \\
NN(5) & 5 & 0.143 & 346 \\
Band width of 0.1 & 4 & 0.123 & 346 \\
Band width of 0.25 & 7 & 0.058 & 346 \\
Band width of 0.5 & 10 & 0.012 & 346 \\
Caliper 0.1 & 5 & 0.112 & 346 \\
Caliper 0.25 & 9 & 0.027 & 346 \\
Caliper 0.5 & 8 & 0.067 & 346 \\
\hline
\end{tabular}

* Number of explanatory variables with no statistically significant mean differences between the matched groups of program and non-program households.

After selecting the best performing matching estimator, the balancing test of covariates before and after matching was checked by applying the selected matching algorithm (Table 4). As the Table indicates, the standardized difference in $\mathrm{X}$ before matching was in the range of $3.7 \%$ and $73 \%$. After matching, the remaining standardized difference of $\mathrm{X}$ for almost all covariates lay between $4.0 \%$ and $18.8 \%$, which is below the critical level of $20 \%$ suggested by Rosenbaum and Rubin [25]. The T-values also indicated that before matching more than half of chosen variables exhibited statistically significant differences, while after matching all the variables have statistically insignificant differences. Thus, the matching process has created a covariate balance between the treatment and control samples which makes it possible to precede the matching procedure (Table 4 ).
Table 4. Propensity score and covariate balance

\begin{tabular}{|c|c|c|c|c|c|c|c|}
\hline \multirow[b]{2}{*}{$\begin{array}{l}\text { Varia } \\
\text { ble }\end{array}$} & \multirow[b]{2}{*}{ Sample } & \multicolumn{2}{|c|}{ Mean } & \multicolumn{2}{|c|}{$\begin{array}{l}\text { Standardized } \\
\text { bias }\end{array}$} & \multicolumn{2}{|c|}{ T-ratio } \\
\hline & & $\begin{array}{l}\text { Tre } \\
\text { ated }\end{array}$ & $\begin{array}{l}\text { Con } \\
\text { trol }\end{array}$ & $\begin{array}{l}\text { Bias } \\
\%\end{array}$ & $\begin{array}{l}(\%) \\
\text { Red } \\
\text { uc }\end{array}$ & $\begin{array}{l}\text { t- } \\
\text { value }\end{array}$ & $P>l t l$ \\
\hline \multirow{2}{*}{ Pscore } & $\begin{array}{l}\text { Unmatc } \\
\text { hed }\end{array}$ & .595 & .595 & 118.1 & \multirow{2}{*}{59.4} & 11.57 & 0.000 \\
\hline & Matched & .557 & .452 & 47.9 & & 1.37 & 0.171 \\
\hline \multirow{2}{*}{ SEX } & Unmatc & .972 & .915 & 24.7 & \multirow{2}{*}{74.5} & 2.37 & 0.018 \\
\hline & Matched & .968 & .954 & 6.3 & & 0.07 & 0.947 \\
\hline \multirow{2}{*}{ EXPR } & Unmatc & 24.3 & 19.2 & 56.9 & \multirow{2}{*}{67.0} & 5.57 & 0.000 \\
\hline & Matched & 23.0 & 21.3 & 18.8 & & 0.16 & 0.874 \\
\hline \multirow{2}{*}{ EDU } & Unmatc & .494 & .422 & 14.6 & \multirow{2}{*}{49.0} & 1.43 & 0.154 \\
\hline & Matched & .484 & .447 & 7.4 & & 0.36 & 0.719 \\
\hline \multirow{2}{*}{ FAMS } & Unmatc & 7.19 & 6.53 & 31.5 & \multirow{2}{*}{51.4} & 3.09 & 0.002 \\
\hline & Matched & 7.11 & 6.79 & 15.3 & & 0.21 & 0.836 \\
\hline \multirow{2}{*}{ DEPR } & $\begin{array}{l}\text { Unmatc } \\
\text { hed }\end{array}$ & 1.16 & 1.33 & -20.7 & \multirow{2}{*}{52.2} & -2.01 & 0.045 \\
\hline & Matched & 1.24 & 1.33 & -9.9 & & -0.08 & 0.937 \\
\hline \multirow{2}{*}{ DSPL } & Unmatc & .526 & .549 & -3.7 & \multirow{2}{*}{$\begin{array}{l}- \\
37.2\end{array}$} & -0.37 & 0.715 \\
\hline & Matched & .522 & .491 & 5.1 & & 0.15 & 0.884 \\
\hline \multirow{2}{*}{$\begin{array}{l}\text { LAN } \\
\text { D }\end{array}$} & Unmatc & .819 & .640 & 41.7 & \multirow{2}{*}{54.9} & 4.09 & 0.00 \\
\hline & Matched & .754 & .673 & 18.8 & & 0.33 & 0.744 \\
\hline \multirow{2}{*}{ TLU } & Unmatc & 1.95 & 1.53 & 36.3 & \multirow{2}{*}{54.9} & 3.52 & 0.000 \\
\hline & Matched & 1.90 & 1.71 & 16.4 & & 0.59 & 0.556 \\
\hline \multirow{2}{*}{ STPS } & Unmatc & .539 & .512 & 5.6 & \multirow{2}{*}{27.9} & 0.55 & 0.585 \\
\hline & Matched & .529 & .509 & 4.0 & & 0.23 & 0.819 \\
\hline \multirow{2}{*}{$\begin{array}{l}\text { DSFT } \\
\text { C }\end{array}$} & Unmatc & .442 & .799 & -73.0 & \multirow{2}{*}{74.3} & -7.00 & 0.000 \\
\hline & $\begin{array}{l}\text { hed } \\
\text { Matched }\end{array}$ & .474 & .565 & -18.7 & & -0.79 & 0.432 \\
\hline
\end{tabular}

$* * *, * *$ and $*$ indicate the level of significance at 1,5 and 10 percent, respectively.

The low pseudo- $\mathrm{R}^{2}$ and the insignificant likelihood ratio tests support the hypothesis that both groups have the same distribution in covariates $X$ after matching (Table 5). These results clearly show that the matching procedure is able to balance the characteristics in the treated and the matched comparison groups. Therefore, the results are used to evaluate the effect of soil and water conservation interventions among groups of households having similar observed characteristics.

Table 5. Chi-square test for the joint significance of variables

\begin{tabular}{lcll}
\hline Sample & Pseudo $\mathbf{R}^{\mathbf{2}}$ & $\mathbf{L R} \mathbf{c h i}^{\mathbf{2}}$ & $\mathbf{p}>\mathbf{c h i}^{\mathbf{2}}$ \\
\hline Unmatched & 0.209 & 111.57 & 0.000 \\
Matched & 0.012 & 2.90 & 0.992 \\
\hline
\end{tabular}

\subsubsection{Average Treatment Effect on the Treated}

This section presents evidence as to whether or not the soil and water conservation program has brought significant changes on the livelihood of the beneficiaries. After controlling for other characteristics, the propensity score matching model using the kernel matching estimator result (band width 0.5 ) indicates the existence of a positive 
additional significant crop production value premium of birr 1,510.42 (US\$ 80.55) per hectare and annual gross income of birr 4,288.29 (US\$ 228.7) for program groups compared to non-program groups. This indicates that on average participant households earned 8.3 percent and 21.2 percent more crop value per hectare and gross household income than the control groups, respectively. The independent analysis result of the data also revealed that the value of crop production was fairly higher on moisture stress program kebeles $(1,771.35 \mathrm{~EB} /$ hectare) than in the high rainfall areas of the program $(1,439.28 \mathrm{~EB} /$ hectare $)$.

Table 6. Average treatment effect of the intervention

\begin{tabular}{llllll}
\hline $\begin{array}{l}\text { Outcome } \\
\text { Variable }\end{array}$ & Treated & Control & $\begin{array}{l}\text { Differe } \\
\text { nce }\end{array}$ & S.E ${ }^{\mathbf{1}}$. & T- value \\
\hline $\begin{array}{l}\text { Value of } \\
\text { crop } \\
\text { production } \\
\text { per hectare }\end{array}$ & 18512.2 & 17001.8 & 1510.4 & 803.54 & $1.889^{*}$ \\
$\begin{array}{l}\text { Annual } \\
\text { gross } \\
\text { income }\end{array}$ & 20189.2 & 15900.9 & 4288.3 & 823.89 & $5.205^{* * *}$ \\
\hline
\end{tabular}

** and * indicate the level of significance at 5 and 10 percent, respectively, ${ }^{1}$ bootstrapped SE.

In order to check for unobservable biases, using Rosenbaum Bounding approach sensitivity analysis was performed on the computed outcome variables. Table 7 presents the critical level of $\mathrm{e}^{\gamma}=1$ (first row), over which the causal inference of significant soil and water conservation effects must be questioned. The first column of the table shows those outcome variables which bear statistical differences between treated and control households in our impact estimate above. The rest of the values which correspond to each row of the significant outcome variables are p-critical values (or the upper bound of Wilcox on significance level -Sig+) at different critical value of $\mathrm{e}^{\gamma}$. The results show that inference for the effect of soil and water conservation does not change, even though the participant and non-participant households were allowed to differ in their odds of being treated up to $200 \%\left(\mathrm{e}^{\gamma}=2\right)$ in terms of unobserved covariates. Thus, it is possible to conclude that our impact estimates (ATT) are insensitive to unobserved selection bias, being pure effects of conservation measures.

Table 7. Results of the sensitivity analysis

\begin{tabular}{|c|c|c|c|c|c|}
\hline Outcomes & $e \gamma=1$ & $\mathrm{e} \gamma=1.25$ & $\mathrm{e} \gamma=2$ & $\mathrm{e} \gamma=2.5$ & $e \gamma=3$ \\
\hline $\begin{array}{l}\text { Value of } \\
\text { crop } \\
\text { production }\end{array}$ & $\mathrm{P}<0.000$ & $\mathrm{P}<0.000$ & 0.000 & $1.10 \mathrm{E}-16$ & $6.20 \mathrm{E} 14$ \\
\hline $\begin{array}{l}\text { Net } \\
\text { household } \\
\text { income }\end{array}$ & $\mathrm{P}<0.000$ & $\mathrm{P}<0.000$ & 0.000 & $\mathrm{P}<0.000$ & $4.70 \mathrm{E}-15$ \\
\hline
\end{tabular}

Note: $\mathrm{e}^{\gamma}(\mathrm{Gamma})=\log$ odds of differential due to unobserved factors where Wilcoxon significance level for each significant outcome variable is calculated

\section{Conclusion and Implication}

This paper examined the impact integrated soil and water conservation interventions on crop production value per hectare and gross income of smallholder farm households in West Harerghe Zone of Oromia Regional State, Ethiopia. The study was based on the data obtained from 398 sample households, consisting 183 soil and water conservation program and 215 non-program participants.

The most widely and intensively used improved land management practices by the program participants $(n=183)$ were soil bud, stone bund, fanya juu, check dam and farm forestry. Out of them 71.0 percent, 53.5 percent, 48.6 percent and 7.1 percent uses soil bund/stone faced soil bund, stone bund, fanya juu and check dam. As well, majority (98 percent) of these households adopted grass strip, mostly with soil and stone bunds and 58.5 percent of them planted different trees on their farm. From the users of the program, only 33.9 percent of the respondents were used a single conservation strategy, while (66.1 percent) used combinations of two, three and more conservation strategies on their plots.

The study empirically demonstrated that integrated soil and water land management program has a significant contribution in increasing crop productivity and hence, increase income to reduce food insecurity of smallholder farmers. These estimated performances of the program also show considerable variability by agro-ecological type of the sampled kebeles. Therefore, it can be concluded that in agriculture dependent country like Ethiopia, soil and water conservation is crucial in improving the livelihoods of the rural farm households. This sends an encouraging signal for program designers, implementers, and funding agents. Thus, to realize the intended outcomes, future development strategies should consider on how to link such interventions with natural resource management based income generating activities that can provide farmers with short term benefits. These estimated performances of the program also show considerable variability by agroecological type of the sampled kebeles. The outcome variability by agro-ecological type, also suggesting a need for the design and implementation of appropriate sitespecific soil and water conservation technologies than blanket recommendation.

Though impact study of a given intervention encompasses the spillover effects on production, income, environment, and on social welfare in general, and soil and water conservation measures have both on-site and off-site effects on society at large. This study limited its scope with the direct effects of the interventions on value of crop production and household income of small holder farmers. Therefore, taking the other livelihood indicators in to consideration is necessary to extend the research work to the other onsite effects and off-site effects of the projects too. In realizing sustainable land management by providing farmers with short-term benefits, the projects linked with natural resources management based income generation at 
household level. Thus, assessment of major constraints and determinants of such income diversification will have immense contribution to scale up the interventions, and hence it is one potential area for research and development. The collectives and the institutional arrangements under each water shade also require the attention of researchers.

\section{Acknowledgements}

The authors would like to thank to Haramaya University for providing financial support for this research through a fund procure from Sweden Government (Sida/ SAREC project).

\section{References}

[1] Nanpham T., D. Yang, S. Kanae, T. OKI , and K. Musiakt, 2001. Application of RUSLE Medel on Global Soil Erosion Estimate. Annual Journal of Hydraulic Engineering, JSCE, Vol.45.

[2] Kertesz A., 2009. The Global Problem of Land Degradation and Desertification. Hungarian Geographical Bulletin, (1): 19-31.

[3] GEF (Global Environmental Facility), 2010. Land Degradation Strategy.

[4] Angima, S. D., Stott, D. E., O'Neill, M. K., Ong, C. K., and Weesies, G. A, 2003. Soil erosion Prediction Using RUSLE for Central Kenya Highland Conditions. Agriculture Ecosystem and Environment, 21: 295-308.

[5] Graaff de. J., C.J. Ritsema and L. Stroosnijder, 2009. Land Degradation and Development Group. Wagningen University, Environmental Service Group.

[6] Bruutrup M., and R. Zimmermann, 2009. Agriculture as the Potential Engine for African Growth and the Role of NEPAD. CESifo Forum. 29p.

[7] Berry, L., J. Olson and D. Campbell, 2003. Assessing the Extent, Cost and Impact of Land Degradation at the National Level: Findings and Lessons Learned from Seven Pilot Case Studies. Commissioned by Global Mechanism with Support from the World Bank. 68p.

[8] Tekalign M., 2008. Opening Address to the $9^{\text {th }}$ Annual Conference of the Ethiopian Society of Soil Science April 172008.

[9] Gete Z., 2000. Landscape Dynamics and Soil Erosion Process Modeling in the Northwestern Ethiopian Highlands. African Studies Series A16. University of Berne Switzerland. Geographica Bernensia.

[10] FAO/WFP (Food and Agricultural Organization/ World Food Program), 2005. Report on the Cost-benefit Analysis and Impact Evaluation of Soil and Water Conservation and Forestry Measures in MERET Project. WFP, Addis Ababa, Ethiopia (Unpublished).176p.

[11] EfD (Environment for Development), 2010. Green Accounting Puts Price on Ethiopian Soil Erosion and Deforestation:http//:www.efdinitiative.org/centers/Ethiopia/the enviroment-for development-imitative: Cited on June 2010
[12] Gete Z., Menale K., John Pender and Mahmud Y., 2006. Stakeholder Analysis for Sustainable Land Management (SLM) in Ethiopia: Assessment of Opportunities, Strategic Constraints, Information Needs, and Knowledge Gaps. Environmental Economics Policy Forum. 97p.

[13] Minale K., 2005. Technology Adoption, Land Rental Contacts, and Agricultural Productivity. PhD Dissertation, Department of Economics and Resource Management, Norwegian University of Life Sciences, Ås, Norway.

[14] Barrett, C. B., J. Lynam, F. Place, T. Reardon, and A.A. Aboud, 2002. Towards Improved Natural Resource Management in African Agriculture. Natural Resource Management in African Agriculture. Undersigning and Improving Current Practices. CAB Publishing: 287-296.

[15] Berhanu G., Gebremedhin W., Yigzaw D., Tilahun G. and Worku T., 2009. Sustainable Land Management through Market-oriented Commodity Development: Case Studies from Ethiopia. Improving Productivity and Market Success (IPMS) of Ethiopian Farmers Project, International Livestock Research Institute (ILRI), Working Paper 21, Addis Ababa, Ethiopia: 46p.

[16] Lakew D., V. Carucci, Asrat Wondemagegnehu and Ytayew Abebe, 2005. Community Based Participatory Watershed Development. Ministry of Agriculture and Development, Addis Ababa, Ethiopia.

[17] Mitiku H., K. Harweg and B. Stillhardt, 2006. Sustainable Land Management: A New Approach to Soil and Water Conservation in Ethiopia. 305p

[18] Bekele S., J. Okello, and V.R. Ratna, 2009. Adoption and Adaptation of Natural Resource Management Innovations in Smallholder Agriculture: Reflections on Key Lessons and Best Practices. Environment, Development and Sustainability, 11: 601-619.

[19] Reddy, V. R., 2005. Costs of Resource Depletion Externalities: A Study of Groundwater Overexploitation in Andhra Pradesh, India. Environment and Development Economics, 10: 533-556.

[20] Kerr, J., G. Milne, V. Chhotray, P. Baumann and A.J. James, 2007. Managing Watershed Externalities in India. Theory and Practice. Environment, Development and Sustainability, (9): 263-268.

[21] WHZBOFED (West Harerghe Zone Finance and Economic Development Office), 2007. Unpublished Annual Report.

[22] PEDBRSO (Planning and Economic Development Bureau of the Regional State of Oromia), 2010. Zonal Atlas of West Harerghe Zone. 112p.

[23] Caliendo, M. and S. Kopeinig, 2008. Some Practical Guidance for the Implementation of Propensity Score Matching, Discussion Paper No. 1588, University of Cologne.

[24] Rajeev H. Dehejia \& Sadek Wahba, 2007. Propensity Score Matching Methods for Non-Experimental Causal Studies.

[25] Rosembaum, P.R. and D.B. Rubin, 1983. The Central Role of the Propensity Score in Observational Studies for Causal Effects, Biometrika, 70 (1): 41-55.

[26] Bryson, A., R. Dorsett, and S. Purdon, 2002. The Use of 

West Harerghe Zone, Ethiopia

Propensity Score Matching in the Evaluation of Labour Market Policies, Working Paper No. 4, Department for Work and Pensions.

[27] Jalan, J. and M. Ravallion, 2003. Estimating the Benefit Incidence of an Antipoverty Program by Propensity-Score Matching. Journal of Business and Economics Statistics, $19-30$.
[28] Heckman, J., Hidehiko, and T. Petra, 1998. Matching as an Econometric Evaluation Estimator: Evidence from Evaluating a Job Training Program. Review of Economic Studies, 64 (4): 605-654. 